\title{
MEDEIROS E ALBUQUERQUE, PAULO MARANHÃO E ISAÍAS ALVES: A ARITMÉTICA CIENTÍFICA DA ESCOLA PRIMÁRIA
}

\author{
MEDEIROS E ALBUQUERQUE, PAULO MARANHÃO AND ISAÍAS \\ ALVES: SCIENTIFIC ARITHMETIC OF PRIMARY SCHOOL
}

\author{
Nara Vilma Lima Pinheiro ${ }^{46}$ \\ Wagner Rodrigues Valente ${ }^{47}$
}

\section{RESUMO}

Este artigo analisa três dos primeiros manuais de práticas aplicadas para uso de testes na escola primária na década de 1920. O primeiro deles, escrito por Medeiros e Albuquerque, Tests: introdução ao estudo dos meios scientificos de julgar a inteligência e a aplicação dos alunos; o segundo, de autoria de Paulo Maranhão, Escola Experimental Testes: testes mentais, testes de escolaridade, programas de testes; e, por fim, Os testes e a reorganização escolar de Isaías Alves. Dada a importância dessas obras como referências para a época, tomamos estes livros como discursos que consolidam representações dirigidas aos professores. A intenção era promover uma transformação na mentalidade e na prática pedagógica dos docentes, com vistas à homogeneização das classes e principalmente dar o que àquela altura era considerada uma base científica à organização escolar. A análise se pautou pelo uso de conceitos vindos da História Cultural, sobretudo os de representação de Roger Chartier (1991) e estratégia de Michel de Certeau (2010), na tentativa de entender que saberes matemáticos elementares foram eleitos e testados para verificar a capacidade intelectual e o rendimento escolar dos alunos das classes primárias.

Palavras chave: Testes Mentais, testes pedagógicos, aritmética, escola primária, manuais de prática aplicada.

\section{ABSTRACT}

This paper analyzes three of the first manuals practices applied to the use of tests in primary school in the 1920s. The first, written by Medeiros e Albuquerque, Tests: introdução ao estudo dos meios scientificos de julgar a inteligência e a aplicação dos alunos; the second, written by Paulo Maranhão, Escola Experimental Testes: testes mentais, testes de escolaridade, programas de testes; and finally $O$ s testes e a reorganização escolar of the Isaías Alves. Given the importance of works as references for the season, take these books and speeches that consolidate representations addressed to teachers. The intention was to promote a change in mentality and teachers' pedagogical practice, with a view to the homogenization of classes and especially to what at that time was considered a scientific basis to the school organization. The analysis was guided by the use of concepts coming of Cultural

\footnotetext{
${ }^{46}$ Doutoranda do Programa de Pós-Graduação em Educação e Saúde na Infância e na Adolescência da Universidade Federal de São Paulo - Campus Guarulhos. naravlp@yahoo.com.br

${ }^{47}$ Livre-docente do Departamento de Educação e professor do Programa de Pós-Graduação em Educação e Saúde na Infância e na Adolescência da Universidade Federal de São Paulo - Campus Guarulhos. Coordenador do GHEMAT (Grupo de Pesquisa em História da Educação Matemática). wagner.valente@unifesp.br

Revista REAMEC, Cuiabá - MT, n.02, dezembro 2014, ISSN: $2318-6674$

Revista do Programa de Doutorado da Rede Amazônica de Educação em Ciências e Matemática http://revistareamec.wix.com/revistareamec
} 


\section{REVISTA REAMEC \\ Revista da Rede Amazônica de Educação \\ em Ciências e Matemática}

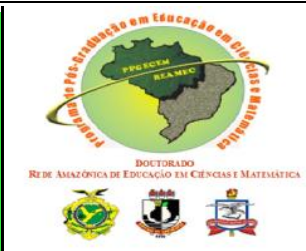

History, especially the representation of Roger Chartier (1991) and Michel de Certeau (2010) strategy in an attempt to understand basic mathematical knowledge who were elected and tested for intellectual ability and academic performance of students in primary classes.

Keywords: Mental tests, pedagogical tests, arithmetic, primary school, manuals of applied practice.

\section{INTRODUÇÃO}

Na década de 1920, as Escolas Normais de várias capitais brasileiras, atentas às Reformas estaduais da Instrução Pública, criaram em suas dependências, laboratórios de psicologia. Esses laboratórios constituirão referência para a ultrapassagem da pedagogia clássica, de vertente filosófica, para afirmar-se uma pedagogia científica, tendo em conta resultados obtidos pela psicologia experimental.

Nessa época, tempos da vaga escolanovista, a psicologia experimental "deveria subsidiar as transformações da escola; as relações professor e aluno, o processo de ensinoaprendizagem, a modernização metodológica, a organização das classes, o conhecimento e o respeito ao desenvolvimento da criança" (ANTUNES, 2007, p. 84). Assim fundamentada, a pedagogia científica se "consolidou pela medida, pelos tests, pelos laboratórios" onde a experimentação desempenhou papel fundamental. Em específico, a utilização dos tests no âmbito escolar foi "a face mais visível" da emergência da pedagogia científica (VALENTE, 2013, p. 1).

Trata-se, pois, de um tempo onde há o fortalecimento do movimento dos testes no Brasil, com a aplicação de testes psicológicos e pedagógicos no ambiente escolar. Com esse movimento assistiu-se à publicação de vários "manuais de aplicação prática" escritos para fundamentar a organização científica da pedagogia e elucidação da realidade escolar. Exemplos disso são os manuais Tests: introdução ao estudo dos meios scientificos de julgar a inteligência e a aplicação dos alunos, de Medeiros e Albuquerque (1924); Testes Pedagógicos e Testes: testes mentais, testes de escolaridade, programas de testes de Paulo Maranhão (1926, 1928); Test Individual de Inteligência e Os testes e a reorganização escolar de Isaías Alves $(1927,1930)$. Tais manuais foram produzidos a partir das experiências de aplicação de testes em escolas primárias brasileiras.

\footnotetext{
${ }^{48}$ Assim como Monarcha (2011, p. 14) adotaremos nesse estudo a denominação de "manuais de aplicação prática" para nos referirmos as publicações editadas pelos "experts em medidas".

Revista REAMEC, Cuiabá - MT, n.02, dezembro 2014, ISSN: 2318 - 6674

Revista do Programa de Doutorado da Rede Amazônica de Educação em Ciências e Matemática

http://revistareamec.wix.com/revistareamec
} 


\section{REVISTA REAMEC}

Revista da Rede Amazônica de Educação

em Ciências e Matemática

Dada a sua importância como obras de referência para a época, tomamos estes livros como discursos dirigidos aos docentes, com o objetivo de promover uma transformação na mentalidade e na prática pedagógica do professorado, com vistas a dar base científica à organização do trabalho escolar.

A análise desses textos considerou, como De Certeau (1991, p.177), que os livros podem ser entendidos ainda, como integrantes de uma estratégia para "legitimar um projeto reformador, ou a justificar para os próprios indivíduos as suas escolhas e condutas".

Tais livros apontam para uma importante fase de apropriação $^{49}$ de ideias que circularam internacionalmente em tempos do movimento dos testes. São obras que constituíram veículos de informação ao professorado brasileiro das novas perspectivas para o trabalho pedagógico, considerado científico, no curso primário. Por meio dessas obras, novas representações ${ }^{50}$ sobre a aprendizagem dos saberes elementares na escola primária entraram em cena quando foram estabelecidas "as constantes do desenvolvimento, os estágios de maturação e a identificação das diferenças individuais" (MONARCHA, 2009, p. 45).

Por certo, em meio a esse movimento de cientifização dos processos escolares, conduzidos através dos testes, aferidos por instrumental estatístico, os ensinos de matemática nos primeiros anos escolares também foram afetados. Programas de ensino, conteúdos a serem ministrados, métodos e avaliação tiveram que ser repensados nessa nova era trazida pelos testes. Assim, interessou-nos saber, a partir da leitura e análise dessas obras, que transformações envolveram a matemática a ser ensinada nos primeiros anos escolares. De modo mais específico, este texto busca a resposta à seguinte questão: que conteúdos matemáticos elementares foram eleitos pelos testes para verificar cientificamente a capacidade intelectual e o rendimento escolar dos alunos das classes primárias?

\section{A REFORMA CARNEIRO LEÃO E A DISSEMINAÇÃO DE UMA NOVA CULTURA PEDAGÓGICA}

\footnotetext{
${ }^{49}$ Nos dizeres de Chartier (1991), a apropriação é o uso e as interpretações que leitor faz do discurso do outro.

${ }^{50} \mathrm{Na}$ concepção de Chartier $(1991,17)$ representações são entendidas como "classificações, divisões e delimitações que organizam a apreensão do mundo social como categorias fundamentais de percepção e de apreciação do real". Embora as representações aspirem à universalidade elas "são sempre determinadas pelos interesses dos grupos que as forjam". Mas elas "não são de forma alguma discursos neutros produzem estratégias e práticas que tendem a impor uma autoridade à custas de outros por ela menosprezados" para justificar suas escolhas.
} 
No Distrito Federal, nos anos 1922 e 1926, Antônio Carneiro Leão se dedicou à reforma da instrução pública. Dentre as providências que tomou destaca-se a adoção dos testes psicológicos e pedagógicos nas escolas públicas primárias da capital. Sua decisão de incluir os testes na rotina das escolas levou Medeiros e Albuquerque - autor a quem este texto dedicará atenção mais adiante - em escrever sobre a temática. Contando com o incentivo de Carneiro Leão, em 1924, Medeiros e Albuquerque publicou a primeira obra brasileira sobre o assunto: Tests: introdução ao estudo dos meios scientificos de julgar a inteligência e a aplicação dos alunos.

A introdução dos testes nas escolas primárias por Carneiro Leão, juntamente com os estudos de Medeiros e Albuquerque provocaram discussões sobre a vantagem e a desvantagem da adoção dessas medidas, formando duas correntes de opiniões distintas. Uma delas, baseada nos princípios psicológicos, achava inoportuna a ideia, já que o Distrito Federal não possuía gabinetes especiais de experimentação e, tampouco, pessoal habilitado para realizar as pesquisas científicas. A outra "com fins exclusivamente pedagógicos, tomava os programas primários e com eles procurava orientar, sob um aspecto diverso, o magistério" (DEODATO MORAES, 1926, p.8).

Em meio a esse embate e "fugindo às pesquisas técnicas" e das orientações dos programas, Paulo Maranhão organizou "sob fundo exclusivamente metodológico, uma série muito grande de provas (testes)" as quais submeteu alunos de diferentes idades e adiantamento. Essas experiências foram realizadas com centenas de alunos de várias escolas do $7^{\circ}$ distrito escolar do Rio de Janeiro. O trabalho desenvolvido por Paulo Maranhão ganhou divulgação como algo diverso àquele das correntes existentes, pois "em logar dos testes se submeterem aos programas, estes é que iam sendo modificados a cada nova experimentação" (DEODATO MORAES, 1926, p.8).

Além de incentivar a publicação de obras que orientassem os professores na implantação de testes no ensino primário das escolas públicas, Carneiro Leão organizou "uma comissão para a determinação de um campo de ação" (PAULILO, 2001, p. 114). Essa comissão era constituída por professores de psicologia da Escola Normal do Rio de Janeiro, pelo inspetor escolar Paulo Maranhão e por professores adjuntos encarregados de auxiliar a comissão nas experiências realizadas. Faziam parte do plano de ação os cursos ministrados, 
em 1924, por Manoel Bonfim ${ }^{51}$ e Maurício de Medeiros ${ }^{52}$. Tratava-se segundo Paulilo (2001, p. 114) de "um curso especial sobre os testes para os diretores de escolas enquanto era experimentado nessas escolas um modelo de aplicação dos testes psicológicos", destinados a preparar o professorado carioca para a renovação dos processos educativos fundamentados "numa representação de educação comprometidos com os métodos ativos de ensino e com a ciência" (PAULILO, 2007, p. 136). A participação de Manoel Bonfim na comissão de implantação dos testes no ensino primário resultou na publicação do livro $O$ método dos testes: com aplicações à linguagem no ensino primário (1926), com colaboração de Ofélia e Narbal Fontes e participação das professoras da Escola de Aplicação do Rio de Janeiro. Utilizando-se das escalas Binet acreditava que os resultados pudessem revelar as características da mentalidade infantil, de modo a contribuir na organização de classes mais homogêneas (GONTIJO, 2010, p.27).

Ao que parece, essa estratégia articulada ao programa de reforma de Carneiro Leão visava transformar a cultura pedagógica do professorado, pois o trabalho conjunto, dos professores adjuntos e autoridades do magistério, funcionava como "estágios durante os quais os professores adjuntos executavam tarefas junto à sedes de inspetorias, na Escola Normal ou nas próprias escolas, adquirindo conhecimento e destreza nos novos processos educacionais" (PAULILO, 2007, p. 137). Posteriormente, de posse dos saberes considerados científicos esses professores atuariam nas demais escolas disseminando a aplicação dos testes. O trabalho precursor de Carneiro Leão em termos de renovação pedagógica e incorporação dos testes psicológicos e pedagógicos teve continuidade na gestão seguinte.

Em 1927, com Fernando de Azevedo na Diretoria Geral de Instrução Pública do Distrito Federal, foi elaborado o anteprojeto para a reforma do ensino público por uma comissão composta por Renato Jardim, ex-diretor; Paulo Maranhão, inspetor escolar; Jonathas Serrano, diretor da Escola Normal; Maria Reis Campos, professora; e Sud Menucci. O

\footnotetext{
${ }^{51}$ Em 1890 Manoel Bomfim (1868 - 1932) formou-se médico pela Faculdade de Medicina do Rio de Janeiro. Ingressou no magistério, em 1898, para lecionar Educação Moral e Cívica na Escola Normal do Rio de Janeiro, mas pouco tempo depois assumiu a cátedra de Pedagogia e Psicologia. No período de 1901 a 1903 frequentou a Universidade de Sorbonne onde estudou com George Dumas e Alfred Binet. De volta ao Brasil, em 1906 reorganizou e dirigiu o primeiro laboratório de psicologia experimental instalado no Pedagogium (ANTUNES, 2001, p. 94).

${ }^{52}$ Irmão caçula de Medeiros e Albuquerque, Maurício Campos de Medeiros (1885 - 1966) formou-se em Farmácia (1903) e Medicina (1907) pela Faculdade de Medicina do Rio de Janeiro, também foi professor de Psicologia da Escola Normal do Rio de Janeiro. Fez vários cursos de especialização na Europa, frequentou os cursos de George Dumas na Sorbonne e ao retornar esteve ligado ao Pedagogium. Foi responsável pela instalação do segundo laboratório de psicologia experimental no Brasil, no Hospital Nacional de Alienados (PENNA \& MASIERO, 2001, p.226).
}

Revista REAMEC, Cuiabá - MT, n.02, dezembro 2014, ISSN: 2318 - 6674

Revista do Programa de Doutorado da Rede Amazônica de Educação em Ciências e Matemática

http://revistareamec.wix.com/revistareamec 


\section{REVISTA REAMEC \\ Revista da Rede Amazônica de Educação \\ em Ciências e Matemática}

trabalho desenvolvido pelas comissões responsáveis pela aplicação dos testes nas escolas primárias teve continuidade até 1928.

No ano seguinte, a Diretoria Geral de Instrução Pública do Distrito Federal promoveu uma série de conferências para tratar de questões referentes à reforma de ensino recentemente aprovada. Participou dessas conferências Lourenço Filho, na época professor da Escola Normal de São Paulo, ministrando duas palestras. Uma tratava da escola nova e a outra da "utilidade dos testes de inteligência no ensino público" (PAULILO, 2007, p. 139). Ao longo de 1929 foram realizadas uma série de dez conferências sobre o ensino técnico profissional. Dessas dez conferências, sete delas, direta ou indiretamente remetiam à discussão sobre os testes, conforme relação abaixo:

I - A escola do trabalho e o curso pre-vocacional, professor Everardo Blackheuser;

II - Escolas e cursos vocacionais, D. Maria dos Reis Campos;

III - Ensino Technico-profissional, professor Álvaro Palmeira;

IV - Testes pedagógicos ou de escolaridade, professor Manuel Bomfim;

V - Testes estalonados e não estalonados, Sr. Medeiros e Albuquerque;

VI - Testes de orientação profissional, professor Plínio Olinto;

VII - A Hygiene dos locais de trabalho, Dr. Barros Barretos;

VIII - Condições do trabalho industrial, Dr. Barros Barretos;

IX - Seleção do operário e adaptação aos ofícios, Dr. Barros Barretos;

$\mathrm{X}$ - As escolas profissionais e sua feição industrial, prof. Edgar Sussekind Mendonça (SERRANO, 1929, p. 22).

Nesse mesmo ano, Lourenço Filho retornou novamente ao Rio de Janeiro para realizar duas novas palestras destinadas aos professores do Município, sobre: Renovação escolar e Testes. Nessas conferências foi saudado por Paulo Maranhão, inspetor escolar dos mais interessados nas duas temáticas abordadas por Lourenço Filho. Juntamente com José Joaquim de Campos Costa Medeiros e Albuquerque, Paulo Maranhão foi precursor na introdução, no Distrito Federal, dos testes de escolaridade para avaliação objetiva do rendimento escolar (PAULILO, 2007).

Em suma, quase toda a década de 1920 assistiu a uma ampla discussão sobre a penetração dos testes na ambiência escolar. Cabe, a partir dessa constatação, analisar mais detidamente as obras de referência desse período, tema deste artigo, buscando resposta para as questões ligadas à matemática dos anos iniciais escolares. Que conteúdos matemáticos elementares foram eleitos pelos testes para verificar cientificamente a capacidade intelectual e o rendimento escolar dos alunos das classes primárias? 


\section{REVISTA REAMEC}

Revista da Rede Amazônica de Educação

em Ciências e Matemática

\section{OS TESTS DE MEDEIROS E ALBUQUERQUE}

José Joaquim de Campos Costa Medeiros de Albuquerque nasceu em 1867, na cidade do Recife, em Pernambuco. Foi jornalista, contista, poeta, teatrólogo, político, professor, fundador da cadeira número 22 da Academia Brasileira de Letras e autor do Hino da Proclamação da República. Em 1897, atuou como diretor da Instrução Pública do Distrito Federal, promovendo uma reorganização do Pedagogium (1890-1919) ${ }^{53}$, o qual deixou de ser um "centro propulsor das reformas e melhoramentos de que carecesse a educação nacional" para se tornar um "centro de cultura superior aberto ao público" (PENNA, 1986, p. 7 apud ANTUNES, 2007, p.68). Nove anos após a criação do Pedagogium, Medeiros e Albuquerque, instalou em suas dependências um laboratório de psicologia experimental e entregou-o a Manoel Bonfim, que o reorganizou e dirigiu por mais de quinze anos (1897-1919).

Segundo Lourenço Filho (1955), Medeiros e Albuquerque sempre se interessou por questões ligadas a medicina, em especial, as de psicoterapia, motivo que o levou a dedicar-se à psicologia. No âmbito brasileiro foi um dos primeiros a divulgar os estudos de Wiliam James e Lang sobre as teorias periféricas das emoções. Também foi pioneiro em escrever sobre psicanálise e sobre testes.

Em 1924, Medeiros e Albuquerque publicou o primeiro livro sobre os processos para medida objetiva e provas mentais no âmbito escolar, sob o título Tests: introdução ao estudo dos meios scientificos de julgar a inteligência e a aplicação dos alunos ${ }^{54}$. Embora fosse a primeira obra brasileira a tratar dos testes, Isaías Alves já trabalhava na adaptação da escala Binet-Simon para o contexto brasileiro. Segundo Abdalla (1998, p. 60) o interesse de Isaías Alves sobre a temática surgiu em 1921 após uma conferência de Medeiros e Albuquerque sobre os testes.

Ao publicar esta obra, a intenção de Medeiros e Albuquerque era trazer para o cenário brasileiro um panorama geral sobre o movimento dos tests, que ocorria nos Estados Unidos. Estruturado em sete capítulos, o livro ainda contava com uma parte destinada uma ampla bibliografia comentada (65 obras em inglês) sobre o que havia de mais moderno, na sua época, em relação aos testes. Um dos fatores que contribuiu na elaboração desse livro foi a constatação da pouca produção francesa sobre o assunto. Embora Alfred Binet tenha sido o

\footnotetext{
${ }^{53}$ Museu pedagógico criado em 1890 no Rio de Janeiro e extinto em 1919. Segundo José Veríssimo (1892) esse instituto "teria a mesma função do Bureau of Education dos Estados Unidos" (Apud Kuhlmann, 2013, p.26).

${ }^{54} \mathrm{~A}$ edição mais antiga que localizamos foi a de 1937 e será sobre ela que teceremos nossa análise.

Revista REAMEC, Cuiabá - MT, n.02, dezembro 2014, ISSN: 2318 - 6674

Revista do Programa de Doutorado da Rede Amazônica de Educação em Ciências e Matemática

http://revistareamec.wix.com/revistareamec
} 
responsável pelo impulso no emprego dos testes, foram os estadunidenses que tomaram a dianteira do movimento, fato comprovado pela enorme quantidade de obras sobre os testes terem sido publicadas nos EUA. De outra parte, a este tempo, o pouco domínio da lingua inglesa pelos professores brasileiros e o alto custos dos livros estrangeiros eram os dificultadores do aprofundamento teórico sobre os testes.

Medeiros e Albuquerque procurava introduzir o leitor nos testes intelectuais mais conhecidos (individuais e coletivos) e discutir o emprego dos testes (de inteligência e pedagógicos) no âmbito escolar.

A princípio, em sua obra, Medeiros e Albuquerque, dava uma noção geral sobre os testes individuais de inteligência de Alfred Binet, escala criada em 1905, "utilizada para calibrar e classificar as capacidades das populações escolares e agrupá-las em classes homogêneas" (MONARCHA, 2009, p. 214). Essa escala foi objeto de várias revisões, em particular, Medeiros e Albuquerque se referia à revisão do próprio Binet, em 1911, e a revisão estadunidense do psicólogo Lewis Terman. Em seguida, no livro, vinham os testes de inteligência coletivos criados pela necessidade de selecionar grandes grupos, testes que inicialmente foram aplicados aos recrutas do exército dos EUA para a primeira Guerra Mundial e que, posteriormente, ganharam os espaços escolares. Como exemplo de testes de inteligência coletivos Medeiros e Albuquerque trazia vários tipos: test dos contrários; test de analogias; test das melhores razões; test de frases desorganizadas; test de provérbios; test de continuação de séries; test de acabamento de phrases. Em particular, interessa a este artigo discutir os tests de continuação de séries por trazer aspectos matemáticos. Seguem, na Figura 1 , os indicadores de tais aspectos.

Figura 1 - Tests de continuação de séries 


\section{REVISTA REAMEC}

Revista da Rede Amazônica de Educação

em Ciências e Matemática

0 test de continuação de séries, se dá, escrevendo certas séries de numeros para que o examinando accrescente mais dois da mesma série.

Exemplo:

$$
\begin{array}{llllll}
3 & 4 & 6 & 9 & 13 & 18
\end{array}
$$

$\begin{array}{llllll}21 & 18 & 16 & 15 & 12 & 10\end{array}$

$\mathrm{Na}$ primeira linha o examinando deve escrever 24 e 31 porque a série está assim organisada 3 $(3+1), \quad(4+2), \quad(6+3), \quad(9+4), \quad(13+5), \quad(18+6)$, $(24+7)$. Na segunda linha os dois numeros seguintes seriam 9 e 6 porque a série está organisada assim: $21,(21-3),(18-2),(16-1),(15-3),(12-2)$. $(10-1),(9-3)$.

Este mesmo test tambem se dá organisando uma série em que falta um numero e pedindo ao examinando que ponha o que falta.

Exemplo:

$$
\begin{array}{rrrrrrr}
3 & 4 & 6 & & 13 & 18 & 24 \\
21 & 18 & 16 & 15 & 12 & & 9
\end{array}
$$

0 examinando teria de escrever na primeira linha o numero 9 e na segunda 10 .

Ha ainda um terceiro modo de organisar o test: é incluindo na série um numero aberrante, que não faça parte della. 0 examinando deve riscal-o. To-

$$
-116-
$$

mando exactamente os dois exemplos, que já nos serviram duas vezes, teriamos:

$$
\begin{array}{rrrrrrrr}
3 & 4 & 6 & 9 & 11 & 13 & 18 \\
21 & 19 & 18 & 16 & 15 & 12 & 10
\end{array}
$$

Os numeros a riscar seriam, na primeira linha, 11 e na segunda 19 .

Para um test com 12 linhas deste genero, mas bastante difficeis, 4 minutos são sufficientes.
Página |

Fonte: MEDEIROS E ALBUQUERQUE, 1937 (p.115 -116)

Para Medeiros e Albuquerque (1937, p. 118) os testes de séries simulavam o mesmo raciocínio intelectual "que leva os homens da sciencia a descobrir as leis naturais. Eles procuram ver na sucessão dos fenomenos qual é o motivo que os faz variar e si, há fenomenos aberrantes, buscam eliminá-los”.

Outro exemplo de teste coletivo de inteligência foram os Tests Nacionaes Intelligencia organizados nos Estados Unidos por uma comissão de psicólogos e educadores americanos: Haggerty, Terman, Thorndike, Wipple e Yerkes. Essa bateria de testes era composta por duas escalas (A e B) e para cada uma delas havia duas séries idênticas e equivalentes de testes. Em seu livro Medeiros e Albuquerque traduziu com algumas adaptações a escala A. O teste $n^{\circ} 1$ dessa escala era composto por 16 pequenos problemas envolvendo em sua maioria o sistema monetário. Exemplos:

(1) Cinco vintens fazem um tostão. Quantos tostões equivalem a uma moeda de prata de $2 \$ 000$ ?

(2) João pagou cinco mil réis, por um relogiosinho de brinquedo e 3 mil réis pela respectiva corrente. Quanto elle pagou pelo relogio e a corrente?

(3) Helena tem 13 annos. Maria tem 9. Quanto Maria é mais moça que Helena? (MEDEIROS E ALBUQUERQUE, 1937, p. 120). 


\section{REVISTA REAMEC}

Revista da Rede Amazônica de Educação

em Ciências e Matemática

Na opinião de Medeiros e Albuquerque as matérias que melhor se adaptavam ao sistema de testes eram a aritmética e a geografia. Em se tratando da aritmética a importância de aplicação dos testes nas escolas se justificava, de acordo com o autor, pela incoerência na correção de provas pelos professores. Havia dois tipos de correção: no primeiro caso os professores davam "notas pelos resultados", e no segundo consideravam a "marcha das operações" perdoando-lhes erros de execução. Essa segunda forma de avaliar era considerada por Medeiros e Albuquerque como absurda, pois o sentido de se aprender aritmética na escola primária era a aplicação na vida prática e nesta esperava-se o resultado certo. Neste sentido os testes de aritmética tinham muito a contribuir, pois visavam "os resultados obtidos - e mais nada” (MEDEIROS E ALBUQUERQUE, 1937, p. 149).

Para auxiliar o professor trazia uma bateria com 15 testes elementares sobre as quatro operações. Estes testes foram aplicados nas escolas de Cleveland, em 1922. Ao que tudo indica, Medeiros e Albuquerque se apropriou dos testes apresentados por Monroe et al $(1917)^{55}$, pois tratava-se dos mesmos exemplos. Além disso, ambos eram uma apropriação dos testes de Courtis. A maioria dos testes tratava das quatro operações fundamentais, dispostas em ordem crescente de dificuldade. Os primeiros eram os mais simples, pois não excediam as unidades. Ao que tudo indica, os testes cujo conteúdo envolvia frações eram os mais difícieis, pois foram oferecidos em apenas duas séries; a primeira delas de soma e subtração com mesmo denominador; a segunda envolvia as quatro operações com denominadores diferentes.

Para Medeiros e Albuquerque (1937, p. 157) a organização de testes que envolviam aritmética era considerada fácil, fossem eles sobre as operações elementares ou sobre problemas, os quais punham "a prova a capacidade de raciocinar dos examinandos". Os testes eram importantes na aritmética, pois permitiam que se percebessem certas particularidades que escapavam aos olhos do professor. Por exemplo, em aritmética era comum se dizer que a ordem das parcelas era indiferente, atendendo à propriedade comutativa dessa operação. Entretanto, a psicologia contestava esta afirmação, pois "é sempre mais fácil somar uma parcela maior com uma menor do que a menor com a maior. E é ainda mais fácil somar duas parcelas iguais". Desse modo, por exemplo, efetuar a operação 3+1, mostrava-se mais fácil do que $1+3$.

\footnotetext{
${ }^{55}$ Monroe, W. S, De Voss, J. C, Kelly, F. J. Educational tests and measurements. Houghton Mifflin Company, New York, 1917.

Revista REAMEC, Cuiabá - MT, n.02, dezembro 2014, ISSN: $2318-6674$

Revista do Programa de Doutorado da Rede Amazônica de Educação em Ciências e Matemática http://revistareamec.wix.com/revistareamec
} 
Os resultados dos testes evidenciavam que os alunos somavam "um número muito maior de parcelas de 1 só algarismos do que outro, embora muito mais pequeno nas parcelas de dois ou mais algarismos; o transporte de dezenas era mais difícil e exigia tempo maior" (MEDEIROS E ALBUQUERQUE, 1937, p. 158).

\section{PAULO MARANHÃO E SUA OBRA ESCOLA EXPERIMENTAL TESTS: TESTES 103 MENTAIS, TESTES DE ESCOLARIDADE E PROGRAMAS DE TESTES}

Embora tenha pertencido ao grupo dos 26 signatários do Manifesto dos Pioneiros da Educação Nova, poucas são as informações sobre Paulo Maranhão. Essa observação se estende aos demais signatários com exceção de "Anísio Teixeira, Lourenço Filho e Fernando Azevedo, sobre quem já foram escritos incontáveis ensaios, teses e livros". Ainda que historiadores e pesquisadores se esforcem para "iluminá-los, ainda há muitas sombras por desvendar a respeito daqueles que contribuíram para tornar ímpar tal momento da história da Educação" (VIEIRA, 2010, p. 11).

O pouco que se sabe sobre Paulo Maranhão indica que durante a reforma Carneiro Leão, ele foi inspetor escolar e responsável pelas experiências desenvolvidas em algumas escolas primárias do Distrito Federal. Com a saída de Carneiro Leão da Diretoria de Instrução Pública do Distrito Federal, Fernando de Azevedo assumiu o cargo de diretor e promoveu uma nova reforma educacional, como mencionado anteriormente. Durante essa reforma, Paulo Maranhão, fez parte do grupo de intelectuais que assinaram os Programmas para os Jardins da Infância e para as Escolas primárias do Distrito Federal organizado em 1929; também foi o responsável pela criação da Coleção Pedagógica de F. Briquet \& Cia.

Na década de 1920, Paulo Maranhão publicou dois livros sobre testes. O que se sabe sobre o primeiro deles, intitulado Testes pedagógicos publicado em 1926, é que se tratava das experiências realizadas no $7^{\circ}$ distrito escolar do Rio de Janeiro para classificação e promoção das classes em 1924 e 1925. Ao final de 1924 foi publicada uma crítica no Jornal do Brasil, na seção Chronicas do ensino, por Alberto Moreira ${ }^{56}$, a qual apontava que o resultado coletado por Paulo Maranhão "não foi positivamente um sucesso, mas deixou esperanças de obter melhores efeitos" com a estalonagem de uma série de testes no decorrer de 1925. (JÚNIOR, 1925, p.6). Foram dois anos para concluir a estalonagem de testes pedagógicos de várias disciplinas da escola primária.

\footnotetext{
${ }^{56}$ Formado em Ciências Jurídicas, em seus textos usava o pseudônimo de Júnior (Jornal do Brasil, 21/08/1929). Revista REAMEC, Cuiabá - MT, n.02, dezembro 2014, ISSN: $2318-6674$ 


\section{REVISTA REAMEC}

Revista da Rede Amazônica de Educação

em Ciências e Matemática

A iniciativa de Paulo Maranhão foi elogiada e ao mesmo tempo criticada por Deodato Morais $^{57}$ (1926). Uma das críticas dizia respeito à padronização das provas, já que Paulo Maranhão não informava o leitor sobre a aplicação desses testes em outras escolas não pertencentes ao $7^{\circ}$ distrito escolar. Outra crítica referia-se ao fato de Paulo Maranhão não orientar os leitores sobre a elaboração dos testes, não fornecia "informações científicas". Infelizmente, até o presente momento, não encontramos nenhum exemplar desse livro.

O segundo livro, publicado em 1928, sob o título de Escola Experimental Testes: testes mentais, testes de escolaridade, programas de testes, não trazia orientação teórica, apenas modelos de testes coletivos de inteligência, testes da várias disciplinas e os principais conteúdos de algumas disciplinas que melhor verificaria o aproveitamento escolar, sob a forma de testes. Ao que tudo indica este segundo livro circulou por mais de vinte anos, pois a $11^{\mathrm{a}}$ edição data de 1950.

Conforme Prefácio de Frota Pessoa, outro personagem também signatário do Manifesto, Paulo Maranhão era "um dos mais devotados e competentes estudiosos dos testes escolares e um constante divulgador de seus processos" no Brasil. Estruturado em três partes, o livro trazia uma variedade de testes mentais (para medir à atenção, à memoria, à associação, à vontade e o raciocínio) e de escolaridade (para medir o rendimento em linguagem, matemática, ciências sociais e ciências).

O livro era indicado aos professores do ensino primário que desejassem "verificar o grau de capacidade mental do educando e examinar objetivamente seu rendimento nos estudos". A ideia de que o professor precisava melhor conhecer a capacidade mental de seus alunos estava pautada nos estudos de Faria de Vasconcelos ${ }^{58}$ o qual considerava que antes de conhecer as matérias de ensino era preciso conhecer "fisiológica e psicologicamente quem se pretende ensinar e educar" (MARANHÃO, 1950, p. 9, grifo do autor). E uma maneira de obter esse conhecimento sobre os educandos referia-se ao uso dos instrumentos da psicologia

\footnotetext{
${ }^{57}$ Em São Paulo foi professor de Pedagogia e de Psicologia Experimental da Escola Normal da Praça. Em 1926 fez parte da comissão de educadores presidida por Carneiro Leão que elaborou o programa para as escolas primárias cariocas. Em 1927 tornou-se membro do conselho diretor da Associação Brasileira de Educação e durante a administração de Fernando de Azevedo foi inspetor escolar do Distrito Federal. Segundo Monarcha (2009, p. 150), Deodato Morais era herdeiro das ideias de Oscar Thompson e estava ligado com as ideias escolanovistas em circulação nos anos 1920, "transitava da condição de instigador de ideias à de protagonista de vanguarda".

${ }^{58}$ António Sena Faria de Vasconcelos Azevedo (1880 - 1939), natural de Lisboa, formado em Direito e Ciências Sociais, foi também professor universitário na universidade Nova de Bruxelas, onde lecionou psicologia e pedagogia. Autor de vários livros, dentre eles Como se ensina à Aritmética. Maiores informações sobre esse autor e suas obras ver Marques (2013).
}

Revista REAMEC, Cuiabá - MT, n.02, dezembro 2014, ISSN: 2318-6674

Revista do Programa de Doutorado da Rede Amazônica de Educação em Ciências e Matemática

http://revistareamec.wix.com/revistareamec 


\section{REVISTA REAMEC}

Revista da Rede Amazônica de Educação

em Ciências e Matemática

experimental, a qual "oferece à prática pedagógica processos apropriados à comprovação do valor de novos sistemas de ensino e do rendimento do trabalho escolar" (MARANHÃO, 1950, p. 10). Segundo Maranhão (1950, p. 11) os testes eram tão importantes para a sociedade da época que já haviam ultrapassado "os limites da escola e se aplicam em todos os campos da atividade social".

A aplicação dos testes possibilitaria ao professor: compreender "o que é fundamental de todas as matérias de ensino"; verificar de modo objetivo e impessoal; permite uma economia de tempo e esforço, pois na maioria das vezes o aluno respondia "com palavras, sentenças curtas, sublinhadas, completa etc.” (MARANHÃO, 1950, p. 64 -65). Isso evidenciava uma nova postura em relação ao modo de avaliar o aluno substituindo a subjetividade das questões, que normalmente exigiam respostas dissertativas, por questões objetivas de assinalar, de completar, dentre outras opções.

Fundamentado nos estudos de Édouard Claparède, Paulo Maranhão, defendia que a escola deveria "inspirar-se numa concepção funcional da educação e do ensino, tomando a criança como centro dos programas e dos métodos escolares e considerando a própria educação como uma adaptação dos processos mentais" (MARANHÃO, 1950, p. 10). Ele ainda apontava a necessidade de adequar os programas de ensino à psicologia da criança. Nesse sentido orientava os professores a consultar simultaneamente os conteúdos dos programas oficiais de ensino e os conteúdos do programa de testes (sugerido em seu livro), para facilitar a elaboração dos testes de rendimento. As questões deveriam abordar "todos os pontos essenciais, por ordem de dificuldade crescente, desprezando as de pouca importância ou inferiores quanto ao sentido geral da expressão" (MARANHÃO, 1950, p.193).

O livro constituía-se por três partes, sendo a primeira referente aos testes mentais com ênfase no coeficiente intelectual ou QI, a partir da obra de Isaías Alves, Teste Individual de Inteligência (1930). Para encerrar a parte teórica desse capítulo trazia as vantagens dos testes coletivos e os inconvenientes dos testes individuais, evidenciando sua preferência pelos testes coletivos. Para auxiliar os professores na escolha desses testes sugeria a Escala Coletiva (Teste Onibus ou Prova dos 100 testes) de P. B. Ballard, perfeitamente adaptada ao âmbito brasileiro para os alunos de 8 a 14 anos e a escala coletiva brasileira, elaborada pelo Superintendente Médico do Departamento de Educacão, Bueno de Andrade, para medir a inteligência das crianças de 7 a 14 anos. Para aplicação dessa escala era necessário que a criança soubesse ler.

Revista REAMEC, Cuiabá - MT, n.02, dezembro 2014, ISSN: 2318-6674

Revista do Programa de Doutorado da Rede Amazônica de Educação em Ciências e Matemática http://revistareamec.wix.com/revistareamec 


\section{REVISTA REAMEC}

Revista da Rede Amazônica de Educação

em Ciências e Matemática

A Escala coletiva de Bueno de Andrade era composta por 62 questões, sendo que as sete primeiras vinham acompanhadas das respostas, para que os alunos entendessem a dinâmica de funcionamento dos testes. A partir da oitava questão os alunos tinham 25 minutos para executarem todas as questões. Das 62 questões, doze delas guardavam aspectos matemáticos. No Quadro 1 têm-se exemplos de testes de acordo com os assuntos tratados:

Quadro 1: Exemplos dos testes da escala Coletiva de Bueno de Andrade

\begin{tabular}{|l|l|l|l|}
\hline Quant. & assunto & Tipo de teste & Exemplo \\
\hline 01 & $\begin{array}{l}\text { Ordenação } \\
\text { numérica }\end{array}$ & Múltipla escolha & $\begin{array}{l}12^{\text {a }} \text { Questão: Quais os números que deveriam estar em } \\
\text { seguida um ao outro? } \\
4-7-9-12-15-5\end{array}$ \\
\hline 02 & problemas & Múltipla escolha & $\begin{array}{l}37^{\text {a }} \text { Questão: Meu avô tem } 5 \text { filhos; cada um destes teve } \\
4 \text { filhos. Quantos primos eu tenho? } \\
18-20-17-15-16-19\end{array}$ \\
\hline 09 & séries & Completar & $\begin{array}{l}13^{\text {a }} \text { Questão: Quais os números seguintes nesta série: } \\
2-4-6-8-\ldots . . . . \\
15-10-9-12-16\end{array}$ \\
\hline
\end{tabular}

Fonte: Maranhão (1950)

Como se observa no quadro 1, a maioria das questões versavam sobre séries numéricas, isto nos leva a conjecturar que a capacidade intelectual do aluno era mensurada, em grande medida, por meio desse conteúdo da matemática escolar.

Além dos testes mentais destinados a medir o QI dos alunos, sugeria também testes que mediam analiticamente as diferentes capacidades da inteligência global: atenção, memória, associação, vontade e raciocínio.

A segunda parte do livro destinava-se a exposição dos testes de escolaridade. Em menos de seis páginas, Paulo Maranhão, dava orientações gerais sobre aplicação desses testes, apresentando as vantagens, o cálculo do tempo de execução pelos alunos, o cálculo da média e o cálculo do mediano. Na sequência trazia 53 testes de linguagem (vocabulário, gramática, composição e leitura silenciosa), 39 testes de aritmética (cálculo e raciocínio), 24 de Ciências Sociais e 10 de Ciências.

Dos 39 testes de aritmética, 28 eram destinados ao cálculo e os demais ao raciocínio, de acordo com a categorização do autor. De modo geral os testes de cálculo tratavam dos 


\section{REVISTA REAMEC}

Revista da Rede Amazônica de Educação

em Ciências e Matemática

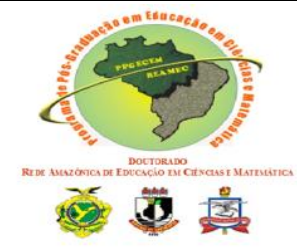

seguintes conteúdos: contagem, as quatro operações, sucessores e antecessores dos números naturais, pares e impares, pequenos problemas envolvendo as quatro operações. Os testes de raciocínio envolviam problemas com dificuldade crescente (fáceis, médios e difíceis).

A terceira e última parte do livro destinava-se ao Programa de Testes, na qual eram indicados os conteúdos que melhor se adaptavam à forma de testes e verificavam o 107 aproveitamento do aluno. Tais conteúdos foram retirados dos programas de ensino das escolas primárias do Rio de Janeiro. As matérias selecionadas foram: linguagem, matemática, ciências sociais e ciências. Ao final do programa de cada matéria havia sugestões dos tipos de testes que poderiam ser elaborados. No caso da matemática os testes deveriam ser de:

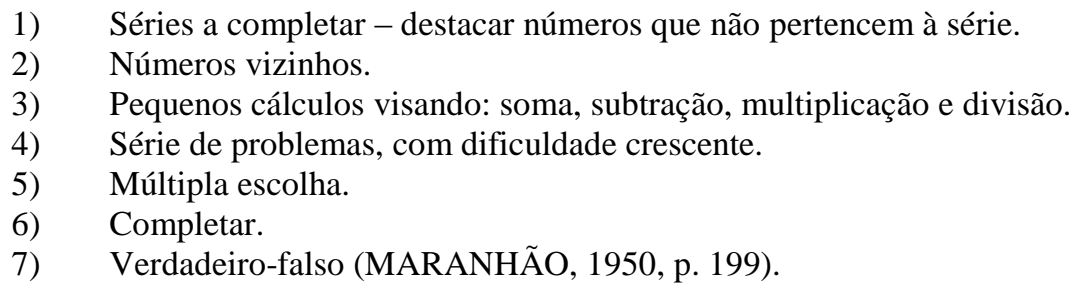

Como se percebe tratavam-se de sugestões para questões objetivas que evitassem a complexidade da resposta a ser dada pelos alunos. Visava economia de tempo e de esforço dos alunos. As experiências com os testes desenvolvidas por Paulo Maranhão, ao que tudo indica, trazem respostas para o modo considerado científico de tratar o ensino da aritmética na escola primária, de organização do programa escolar. Conteúdos são selecionados a partir da testagem.

Mas esse modo científico de tratar os conteúdos não agradava a todos. Nas seções Crônicas do ensino do Jornal do Brasil, elaboradas por Alberto Moreira, tem-se críticas relacionadas às experiências realizadas nas escolas primárias do Rio de Janeiro por inspetores escolares, sobretudo aquelas desenvolvidas por Paulo Maranhão. Embora reconheça os esforços de Paulo Maranhão, "um trabalhador infatigável, um exemplo de operosidade edificante", Alberto Moreira advoga que ele tem poucos conhecimentos sobre a psicologia experimental, a qual "exige uma técnica complicada de psicologia geral para substituir a aparelhagem usada na psicologia experimental, difícil de manter fora dos laboratórios que se criaram os testes". Considerava que Paulo Maranhão não tinha preparo suficiente em psicologia para escrever sobre o assunto, mesmo os mais experientes "os verdadeiros técnicos, como Manoel Bomfim, caminham tateando". Por esse motivo, defendia que os testes pedagógicos elaborados por Paulo Maranhão não atendiam os preceitos da psicologia 


\section{REVISTA REAMEC}

Revista da Rede Amazônica de Educação

em Ciências e Matemática

experimental, tratavam-se apenas de questionários sobre a matéria ministrada em aula (MOREIRA, 1929, p. 7). E que essa prática de organizar questionários

é uma velha prática pedagógica, sempre realizada com sucesso pelo nosso professorado. Não há professor em todo Brasil que não tenha organizado um problema semelhante aos citados pelo Sr. Paulo Maranhão como do notável Ed. Ley de Londres e se não tenha servido dele para aferir conhecimentos dos seus alunos" (MOREIRA, 1929, p. 7)

Em se tratando de conhecimentos sobre a psicologia experimental, na opinião de Alberto Moreira, quem melhor poderia tratar o assunto era a obra de Anselmo Gonzalez Technica de Psychologia Experimental sem aparelhos, obra conhecida do professorado. Sobre esse manual, Alberto Moreira, pensava em organizar uma conferência na Associação Brasileira de Educação para tratá-lo com minúcia.

Em outras críticas, Alberto Moreira, deixa claro que era partidário dos testes mentais, mas tinha restrições quanto aos testes pedagógicos por eles serem elaborados por profissionais que não tinham conhecimentos psicológicos e principalmente por eles (os testes) tenderem a substituir os exames de verificação do aproveitamento dos alunos.

Acompanhando as críticas de Alberto Moreira no Jornal do Brasil no período de 1925 a 1929 percebe-se uma resistência em aceitar os testes pedagógicos como o instrumento capaz de fundamentar cientificamente os problemas pedagógicos. Essa resistência partia, sobretudo, de profissionais diretamente ligados à psicologia, que não viam com bons olhos, as apropriações de seus resultados pela pedagogia.

\section{ISAÍAS ALVES E OS TESTES E A REORGANIZAÇÃO ESCOLAR}

Nascido em 1888, no interior da Bahia, Isaías Alves formou-se em Direito, mas seguiu o caminho da educação como professor do Ginásio Ipiranga e no Ginásio da Bahia. Em 1926, publicou seu primeiro livro sobre testes, intitulado Teste Individual de Inteligência. Nesse livro, Isaías Alves, defendia a aplicação de testes de inteligência para a organização de classes homogêneas.

Isaias Alves fez parte do grupo de intelectuais brasileiros que fizeram curso de mestrado, em 1930, na Universidade de Colúmbia, nos Estados Unidos. Seu interesse principal nesse curso era estudar os testes psicológicos, sob orientação de Edward Lee Thorndike, um dos principais psicólogos da época, a quem Isaías apresentou os resultados do seu segundo livro Os Testes e a Reorganização Escolar (WALGER, 2006, p. 32). Em tempos 


\section{REVISTA REAMEC}

Revista da Rede Amazônica de Educação

em Ciências e Matemática

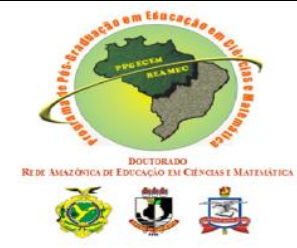

de publicação dessa obra, Isaías Alves era comissionado do Governo do Estado da Bahia, para orientar o professorado primário nos estudos dos testes mentais e pedagógicos.

Não demorou muito para que essa publicação passasse a fazer parte do quadro de referências para introdução ao estudo dos testes pelo professorado paulista. O livro fez parte da lista de obras sugeridas pela revista Escola Nova, de 1931, sob a edição de Lourenço Filho.

Conforme se lê no prefacio de Anísio Teixeira (1930, p. I) o livro era destinado aos professores e o assunto era tratado "nitidamente do ponto de vista técnico, descendo a detalhes de construção e estandardização dos testes, que julgaríamos demasiados se não soubéssemos que a justificação deles e a perfeita compreensão de suas bases científicas, exigem, ainda entre nós, tais explicações".

Os testes e a reorganização escolar era resultado do curso de Medidas da Inteligência e dos resultados escolares, realizado em dez aulas, em 1928, pela Diretoria Geral de Instrução Pública do Estado da Bahia. A ideia principal de sua obra era a reorganização escolar por meio da aplicação de testes de inteligência e, consequentemente, a homogeneização das classes.

O livro trazia uma visão geral dos testes de inteligência e dos testes pedagógicos, desde o ponto de vista teórico, quanto do ponto de vista prático. Nessa obra discutia o Teste individual de Binet; Testes coletivos de inteligência; Testes Pedagógicos; Testes de Ortografia, Caligrafia, Geografia, História, Aritmética, Ciências Físicas e Naturais.

Os primeiros testes coletivos organizados sistematicamente com o intuito de medir a inteligência de muitos indivíduos ao mesmo tempo, foram aplicados pelas Forças Armadas dos Estados Unidos, testes Alpha e Beta. A bateria de testes Alpha foi organizada para medir somente os recrutas que sabiam ler e escrever. Para os que não eram alfabetizados foram criados os testes Beta. Os testes Alpha eram formados por uma série de 212 questões distribuídas em 8 grupos. Para ser classificado com uma capacidade muito superior bastava responder corretamente 135 questões das 212.

O teste $\mathrm{n}^{\circ} 2$ era composto de " 20 problemas de aritmética, muito simples alguns, e poucos de relativa complexidade", os quais deveriam ser resolvidos em 5 minutos. Exemplos:

1) Quantos são 30 homens mais 7 homens?

7) Quantos cigarros se podem comprar com 50 centavos a razão de 2 por 5 centavos? 
11) Um negociante comprou algumas mulas por 1: 600\$000. Vendeu-se por 1:800\$000, ganhando $40 \$ 000$ em cada mula. Quantas eram elas?

20) Um fornecedor que havia entregue 1897 caixas de maçãs a um acampamento, forneceu o resto do seu stock a 20 ranchos do exército. Desta quantidade restante, cada rancho recebeu 54 caixas. Qual o número total de caixas fornecidas (ALVES, 1930, p. 83).

$O$ teste $n^{\circ} 6$ consistia em completar uma sequência de números na ordem crescente ou 110 decrescente obedecendo as regras de fácil percepção. Exemplo:

$$
\begin{array}{r}
3-4-5-6-7-8-\ldots . \\
10-15-20-25-30-\ldots .
\end{array}
$$

As informações sobre os testes Alfa foram trazidas por Isaías Alves apenas para conhecimento do professor. Os testes que adaptou para uso estandardizado nas escolas primárias da Bahia foi o Teste Coletivo de Inteligência organizado por P. B. Ballard (M. A., D. L.). Após a adaptação, esse teste passou a denominar-se Teste Coletivo de Inteligência forma bahiana de Isaías Alves. Essa versão tratava-se de uma bateria de testes composto por: teste I - ordens a obedecer; teste II - sentenças desorganizadas; teste III - analogias; teste IV - séries numéricas; teste V - Melhor razão; teste VI - senso comum. Cada teste desses deveria ser resolvido em cinco minutos. Em particular o teste de séries numéricas era composto por 16 séries.

A segunda parte do livro de Isaias Alves destinava-se a apresentação de testes pedagógicos. Inicialmente tratava de convencer o professorado sobre as vantagens em relação as provas tradicionais. Para esse autor havia três categorias de testes pedagógicos: testes de prática, testes de informação e testes de estandardizados. Os testes de prática eram utilizados "nas aulas bem organizadas" nas escolas estadunidenses. Eram "verdadeiros cursos graduados que vão obrigando os alunos a exercícios repetidos e systematizados”. Exemplo desse tipo são os testes de aritmética de Courtis e os testes de Leitura ou Lições-Testes de Mc. Call. Além de serem reconhecidos como testes de práticas também eram de estandardização.

Os testes de informação eram exames periódicos que o professor deveria repetir durante ano escolar para verificar, mensalmente ou quinzenalmente, o progresso dos alunos para se estabelecer os objetivos do ensino.

Em seu livro Isaías Alves (1930) trouxe alguns exemplos de testes pedagógicos, estandardizados por especialistas dos EUA, a serem aplicados nas escolas primárias: teste de leitura - May Ayres Burgess; Lições - testes - Mc. Call; testes de leitura primária e os testes 


\section{REVISTA REAMEC}

Revista da Rede Amazônica de Educação

em Ciências e Matemática

de leitura silenciosa - Arthur Gates; Teste de leitura em voz alta - William Gray; Teste de Diagnostico de linguagem - Franscen; Testes de ortografia - Thorndike, Leonand Ayres e Jones; Teste de Caligrafia - Thorndike, Leonand Ayres; Teste de Aritmética - Courtis.

Segundo Alves (1930, p. 148) "enquanto a leitura silenciosa era a base de cultura científica, literária e cívica, o cálculo aritmético era necessário para a economia”. Por isso, o 111 ensino nos EUA deu "maior eficiência na educação aritmética dos meninos". Nesse sentido, os estadunidenses consideravam que para uma boa educação em aritmética não era necessário problemas complicados e operações longas, bastava apresentar aos alunos "exercícios simples e rápidos, de dificuldade suavemente crescente, como degraus higiênicos de uma escada que não cansa". Essa recomendação era indicada tanto para pequenos problemas quanto para as quatro operações, as quais deveriam apresentadas "com números de poucos algarismos até que o aluno se sinta à vontade na execução de qualquer conta”. Tal como nos EUA, Isaías Alves salientava a importância de pequenos exercícios repetidos ao invés de grandes contas.

Os testes para a aritmética que seriam adaptados por Isaías Alves ainda estavam em fase de experimentação, mas mesmo assim indicava em seu livro os testes estandardizados por Courtis, que serviam "de exame e ao mesmo tempo de curso" (ALVES, 1930, p. 149 grifo do autor). Tratava-se de uma bateria de testes composto por 48 cartões. $\mathrm{O}$ primeiro cartão era constituído por 72 operações de adição envolvendo os números naturais de 0 a 9 . Na figura 2 têm-se onze exemplos da operação de adição utilizada nos testes de Courtis.

Figura 2: Teste de aritmética de Courtis

$\begin{array}{ccccccccccc}6 & 8 & 4 & 2 & 5 & 6 & 4 & 3 & 4 & 4 & 9 \\ 3 & 4 & 7 & 4 & 0 & 7 & 2 & 6 & 9 & 2 & 6 \\ 1 & 7 & 4 & 6 & 2 & 5 & 3 & 8 & 6 & 9 & 8 \\ - & - & - & - & - & - & - & - & - & - & -\end{array}$

Fonte: ALVES (1930, p. 149)

O tempo de execução do primeiro cartão variava de acordo com o grau de ensino, por exemplo, se os alunos pertencessem ao $6^{\circ}$ grau o tempo de realização era de 4 minutos, se pertencessem ao $8^{\circ}$ grau deveria executar em 3 minutos, se fossem do $4^{\circ}$ grau inferior o tempo era de 6 minutos e 25 segundos. As operações eram realizadas em papel transparente, estendido sobre o cartão. Os resultados das operações ficavam no verso do cartão para o aluno conferir. 


\section{REVISTA REAMEC}

Revista da Rede Amazônica de Educação

em Ciências e Matemática

Todas as demais operações elementares eram realizadas "com grande variedade de exemplos, não havendo, em mais de 600 cálculos, uma só conta de dividir em que o divisor tenha mais de quatro algarismos" (ALVES, 1930, p. 150).

\section{CONSIDERAÇÕES}

No decorrer da década de 1920 a psicologia de base experimental desempenhou um papel de fundamental importância nas orientações dadas às práticas escolares do ensino primário. A este tempo foram publicadas obras de referência sobre o emprego de testes no âmbito educacional brasileiro. Tais obras procuravam evidenciar a importância de testes como base científica para se discutir melhorias no ensino, e prescrever modelos de testes estandardizados.

Trata-se de um tempo de afirmação do uso de resultados da psicologia experimental pela pedagogia. E, como se viu, esse processo ocorreu com embates que buscavam desqualificar o modo pedagógico de tratar os resultados laboratoriais nas orientações didáticopedagógicas dadas aos professores. No entanto, se a princípio as apropriações da psicologia experimental pela pedagogia foram alvo de críticas, com o passar do tempo, observa-se um detalhamento grande dos processos e dinâmicas de uso dos testes - e o estudo de Isaías Alves é exemplo disso - de maneira a afastar críticas vindas da psicologia.

De modo geral, nas obras consultadas, identificamos que os testes coletivos de inteligência apresentavam aspectos matemáticos cuja intenção era medir o raciocínio dos indivíduos. Esses aspectos se apresentavam nos padrões e regularidades a serem encontrados e observados nas sequências numéricas. Ao que tudo indica, este foi o conteúdo eleito para verificar cientificamente a capacidade intelectual dos indivíduos.

Em se tratando dos testes de escolaridade para a aritmética verificamos que os testes apresentados por Medeiros e Albuquerque se limitavam apenas às quatro operações elementares e às frações, cuja intenção era medir as habilidades de efetuar as técnicas operatórias do cálculo. Os testes de Courtis indicados por Isaías Alves também tinham as mesmas características.

Diferentemente dos testes apresentados por Medeiros e Albuquerque e Isaías Alves, o livro de Paulo Maranhão trazia modelos que testavam, além das habilidades de efetuar as técnicas operatórias do cálculo, o raciocínio por meio de problemas. Paulo Maranhão se preocupava em adaptar os conteúdos dos programas escolares ao formato dos testes, na Revista REAMEC, Cuiabá - MT, n.02, dezembro 2014, ISSN: 2318 - 6674 


\section{REVISTA REAMEC \\ Revista da Rede Amazônica de Educação \\ em Ciências e Matemática}

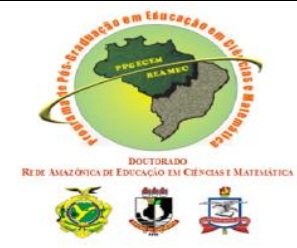

tentativa de adequar o ensino a ordem psicológica da criança. Isto justifica a elaboração de um programa de testes para a escola primária. Ao fazer isto buscava dar cientificidade ao trabalho pedagógico.

Das três obras analisadas, Medeiros e Albuquerque foi o único que apontou uma particularidade obtida com a aplicação de testes aritméticos para a operação de adição. 113 Indicou que a propriedade comutativa da adição não se aplicava psicologicamente ao ensino primário, ainda que em termos matemáticos a propriedade fosse inquestionável. A nosso ver, era uma tentativa de convencer o professor a considerar a ordem psicológica de aprendizagem das crianças, ao invés de considerar apenas a ordem dos conteúdos dos programas de ensino. Uma tentativa de passagem da ordem lógica dos ensinos de matemática, para a ordem psicológica desses mesmos ensinos.

\section{REFERÊNCIAS}

ABDALLA, I. G. Ter Equilíbrio, para dar equilíbrio - Profissão psicólogo? Um estudos sobre as representações sociais dos alunos de um curso de Psicologia. São Paulo: Arte \&Ciência, 1998.

ALVES, I. Os testes e a reorganização escolar. Prefácio de Anísio Spinola Teixeira. Bahia: Nova Gráfica, 1930.

ANTUNES, M. A. M. A psicologia no Brasil: leitura histórica sobre sua constituição. São Paulo: Educ, 1998, 5ª Ed. 2007.

. Manoel José do Bomfim (1868 - 1932). In: CAMPOS, R. H. de F (org.). Dicionário Biográfico da Psicologia no Brasil. Rio de Janeiro: Imago Ed.; Brasília, DF: CFP, 2001.

CHARTIER, R. O Mundo como representação. In: Estudos Avançados 11(5) IEA - USP. São Paulo, 1991.

DEODATO MORAES, P. de M. Tests Pedagógicos. Jornal do Brasil, Rio de Janeiro, 1 de abril de 1926, p. 8.

EDITAL DOS NOVOS PROGRAMAS. Jornal do Brasil. Fundação Biblioteca Nacional, Rio de Janeiro, 28 de julho de 1926, p. 13.

JÚNIOR. Chronicas do Ensino. Jornal do Brasil. Fundação Biblioteca Nacional, Rio de Janeiro, 28 de janeiro de 1925, p. 6.

GONTIJO, R. Manoel Bomfim. (Coleção Educadores). Recife: Fundação Joaquim Nabuco, Editora Massangana, 2010.

LOURENÇO FILHO, M. B. A Psicologia no Brasil. In: AZEVEDO, F. As ciências no Brasil. São Paulo: Melhoramentos, 1955.

MARANHÃO, P.. Escola Experimental: testes mentais, testes de escolaridade e programa de testes. São Paulo: Livraria Francisco Alves, 1945. 


\section{REVISTA REAMEC \\ Revista da Rede Amazônica de Educação \\ em Ciências e Matemática}

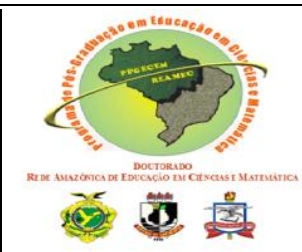

MARQUES, J. A. de O. Manuais pedagógicos e as orientações para o ensino de matemática no curso primário em tempos de Escola Nova. Dissertação (Mestre em Ciências). Guarulhos: Universidade Federal de São Paulo, 2013.

MEDEIROS E ALBUQUERQUE. Tests: introdução ao estudo dos meios científicos de julgar a inteligência e aplicação dos alunos. Rio de Janeiro: Livraria Francisco Alves, 1937.

MOREIRA, A. Chronica do Ensino: escola experimental. Jornal do Brasil. Fundação Biblioteca Nacional, Rio de Janeiro, 31 de maio de 1929, p. 7.

PAULILO, L. A. Reforma educacional, sistema público de ensino no Distrito Federal na década de 1920: tensões, censuras e conflitos em torno da educação popular. Dissertação (Mestre em Educação). São Paulo: USP. 2001.

A estratégia como invenção: as políticas públicas de educação na cidade do Rio de Janeiro entre 1922 e 1935. Tese (Doutor em Educação). São Paulo: USP. 2007.

PENNA, A. G.; MASIERO, A. L. Maurício Campos de Medeiros (1885 - 1966). In:

CAMPOS, R. H. de F (org.). Dicionário Biográfico da Psicologia no Brasil. Rio de Janeiro: Imago Ed.; Brasília, DF: CFP, 2001.

SERRANO, J. Edital. Jornal do Brasil. Fundação Biblioteca Nacional, Rio de Janeiro, 16 de maio de 1929, p. 22.

VALENTE, W. R. A Era dos Tests e a Pedagogia Científica: um tema para pesquisas na Educação Matemática. Revista Acta Scientiae, v. 16, p. 11-26, 2014a.

VIEIRA, S. L. Frota Pessoa. Coleção Educadores. Recife: Fundação Joaquim Nabuco, Editora Massangara, 2010, 160p. Disponível em http://www.dominiopublico.gov.br/download/texto/me4700.pdf Acesso em 10 jun. 2014.

WALGER, A. A. R. Psicometria e educação: a obra de Isaías Alves. Tese de doutorado. São Paulo: Pontifícia Universidade Católica, 2006. 